\title{
Teaching and Learning Conference-within-a-Conference Launched at APSA Annual Meeting in Boston
}

\author{
Alison Rios Millett McCartney, Towson University \\ Renée Van Vechten, University of Redlands
}

S ince 2004, APSA has held an annual Teaching and Learning Conference (TLC) to bring together political scientists who seek to advance their pedagogical skills, knowledge, and pedagogyrelated research. Part of APSA's mission is to widen opportunities for professional development and increase access to teaching and learning resources for all political scientists, especially those who work at institutions where teaching constitutes a substantial portion of their professional responsibilities, such as those at regional comprehensive universities, liberal arts colleges, and community colleges. Given factors including APSA members' limited travel budgets and APSA's aim to disperse teaching resources more widely, APSA facilitated and funded a day-long symposium at this year's annual meeting for those interested in political science education: the TLC at APSA. This full-day conferencewithin-a-conference took place on September 1, 2018 with the theme, "Political Science in Contentious Times." The event sought to complement the standalone TLC that will move to a biennial schedule starting in 2020. TLC at APSA's goals include promoting the scholarship of teaching and learning, equipping faculty with new techniques and resources for teaching, fortifying the role of teaching in the discipline, and enhancing the annual meeting experience for attendees.

\section{CONFERENCE STRUCTURE}

To differentiate the conference-within-aconference from regular panels and short courses that populate the annual meeting program, the planning committee for TLC at APSA devised a program distinguished by varied elements: teaching cafés, workshops, and themed tracks that facilitated not only deeper engagement with the scholarship of teaching and learning (SoTL) but also acquisition of innovative tools for teaching political science; meals including breakfast with a plenary speaker, a hosted lunch, and a closing reception helped unify the activities and encouraged networking among attendees.

The committee included cochairs Alison Rios Millett McCartney (Towson Univer- sity) and Renée Van Vechten (University of Redlands and APSA Council member) and committee members Victor Asal (SUNY Albany), Simulations and Games Track Moderator; Elizabeth A. Bennion (Indiana University South Bend), Civic Engagement Education Track Moderator; Tressa Tabares (American River College), Technology and Innovative Pedagogy in the Classroom Track Moderator; and plenary speaker Nancy Thomas, Institute of Democracy \& Higher Education at Tufts University, Jonathan Tisch College of Civic Life. The committee prioritized proposals that explored needs of the teaching profession, fit the TLC format, and addressed significant issues in political science pedagogy.

Over 225 people attended the event, surpassing the initial estimate of 150 . By including participation in the regular conference fee, the association helped demonstrate its commitment to one of its core objectives: "promoting high quality teaching and education about politics and government." Sponsors included the Jonathan Tisch College of Civic Life's Institute of Democracy \& Higher Education at Tufts University, CQ Press, the Political Science Education Section, and the APSA Committee on the Status of Community Colleges in the Profession.

Morning workshops introduced instructional strategies and tools for use in a variety of educational settings. Maureen Feeley focused on peer instruction in large enrollment courses, while Patrick McGovern, Christina Sciabarra, John Willerton, and Mikhail Beznosov tackled the teaching of conflict. Chad Raymond demonstrated how to bring design thinking into teaching with student-designed games, and Victor Asal trained instructors in international relations games. Michelle Deardorff and Jean Harris led a session about facilitating political science discussion in a "Trump world."

Following a buffet luncheon sponsored by CQ Press, attendees engaged in one of four separate teaching cafés, or 45-minute workshops designed to spur interest, start conversations, and develop skillsets. Amber Dickenson and Eric French instructed attendees in developing a formal training program for teaching assistants, while
Jeff Harden and Melissa Harden concentrated on strategies to improve information literacy among political science undergraduates. Clarissa Estep and Eric Myers demonstrated how to integrate virtual reality into the classroom, and Tomer Perry demonstrated how to teach ethics through tabletop game design.

To promote deeper engagement with scholarship in specific areas of concentration, three separate tracks (selected based on the popularity of tracks at previous TLCs) occupied the afternoon sessions: civic engagement, simulations and games, and technology and innovative pedagogy. In the tradition of reporting TLC proceedings, summaries of the tracks follow.

\section{CIVIC ENGAGEMENT EDUCATION Judithanne Scourfield McLauchlan and Elizabeth A. Bennion}

Participants in the Civic Engagement Education track discussed how to build students' civic capacity through innovative and traditional course assignments focused on civic engagement learning goals. Online discussion forum assignments can build deliberative civic engagement skills, while a series of civics projects can be used in both online and face-to-face classes to teach students the skills they need to become politically engaged. Content-flexible courses, including research methods, can be redesigned to integrate civic engagement learning goals through experiential learning projects, while civic engagement centers can provide support for such curricular reforms.

Political scientists' approach to teaching civic and political engagement reflects the contentious times in which we live. For example, a campus-wide debate surrounding a divisive guest speaker inspired a series of "deliberation cafés" to develop a "collective toolbox of democratic practices: careful listening, inclusive participation, and the collective identification of ways to move forward." There is no doubt that the wider political climate affects instructors' teaching decisions, and it is important to accept the fact that students' understanding of how politics works will not always produce trust in government, but can, instead, produce 
an increase in informed cynicism. Luckily, an unprecedented number of groups are devoted to mobilizing college students to vote and become active participants in all levels of our political system. Political scientists in every disciplinary subfield should be a critical part of this process.

\section{SIMULATIONS AND GAMES}

\section{Megan Becker and Lucy Goodhart}

These panels showcased examples of simulations and games used in classroom settings and offered opportunities for discussion of best practices and the place of simulations within political science's pedagogical toolkit.

A major theme of the discussion was how to use simulations most effectively. Consensus reflected the need for intentionality in planning and the importance of faculty as guides in the process, particularly when things do not go as envisioned. In planning, faculty should have explicit goals and design simulations to achieve them. For example, when balancing the tension between realism and tractability, faculty should instead consider specificity. How much detail is needed to achieve specific pedagogical goals? Let the answer lead the planning process.

During the simulation, faculty must be aware that, while immersive experiences inspire engagement, they can also generate intense interactions and reactions. More reticent students may therefore benefit from help in navigating in-person discussions or may be more comfortable with online interactions. Whether online or faceto-face, faculty should include a regularized debriefing process-before, during, and after the simulation-as appropriate. Ask students to consider the questions: What just happened? So what? Now what?

So what about simulations and games in political science? Students learn to think like political scientists. Within simulations, students act out a simplified version of our "mental maps," increasing the likelihood that they grasp and retain core concepts.

Now what? We will make simulations a signature pedagogy, developing innovative simulations and games, and establishing metrics to demonstrate their effectiveness in the classroom.

\section{TECHNOLOGY AND INNOVATIVE PEDAGOGY IN THE CLASSROOM Tressa Tabares}

As the topic of this track's panels suggest, the presentations provided a wide range of examples of creative ways to respond to new and ongoing challenges in the political science classroom.

A major theme that emerged was that innovation in pedagogy and use of technology as a teaching and learning tool are often fueled by a need and desire to recognize and respond to who our students actually are,

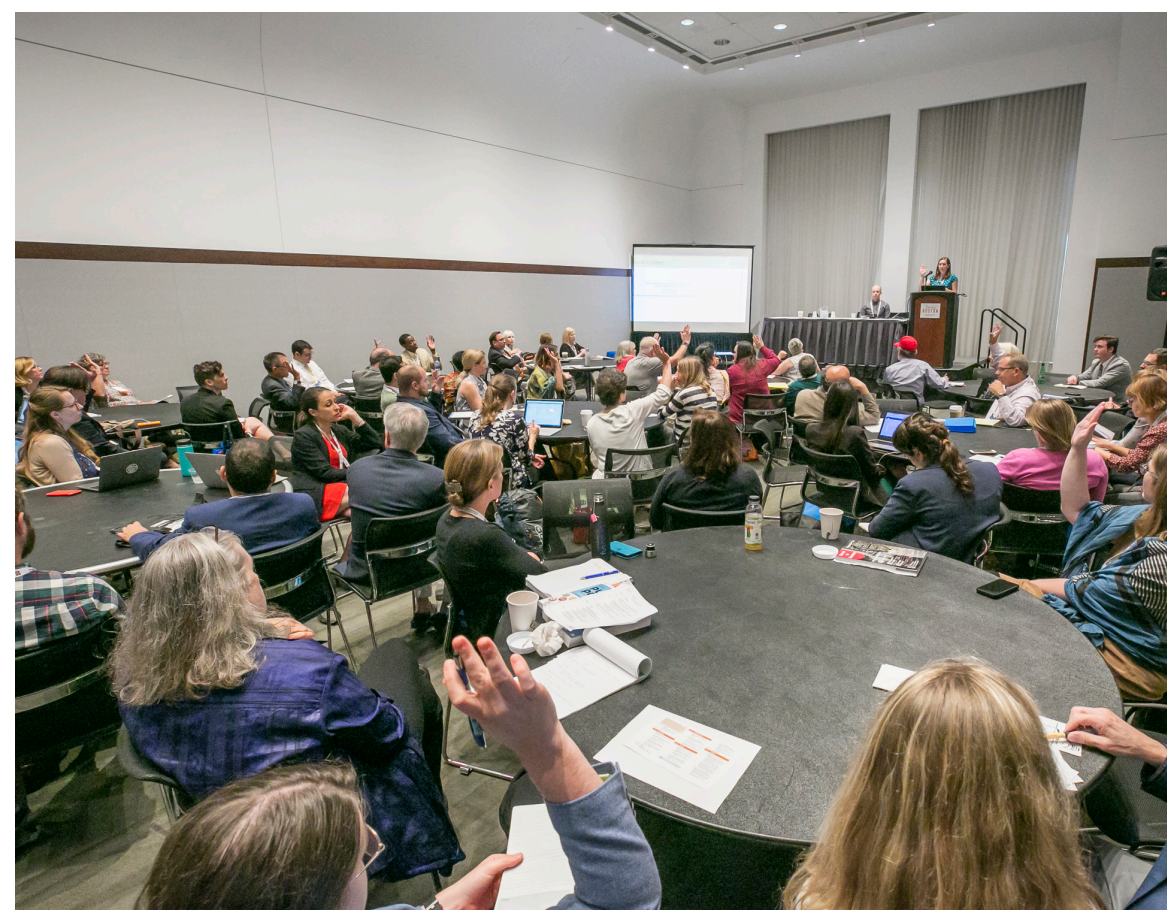

TLC at APSA attendees participate in a presentation during the first half of the day.

meet them where they are, and provide them with what they need to be successful not only in our classes but on their chosen educational and career paths.

Enhancing all of our students' interest in and engagement with the political world and helping them acquire and demonstrate marketable skills were noted as common reasons for trying something new in the classroom, whether it be incorporating songs and cartoons as learning materials, using a gradual immersion strategy to teach in a bilingual classroom based on the skills of the incoming students, building an open access textbook for quantitative research methods to overcome barriers of cost and provide opportunities for applied and skillsbased learning, creating opportunities for students to become active participants in their own learning through structured small group assignments, or leveraging technology to maximize students' access to courses taught by experts.

Our students come to us with a wide range of previous knowledge, personal experience, interests, skills, resources, and goals. Recognizing this starting point is an important step to providing a meaningful learning experience for all students.

\section{CONCLUSION}

The first TLC at APSA provided a collaborative, interactive setting in which participants could deepen their pedagogy and expand their professional networks. Attendance at scheduled events varied throughout the day as attendees circulated between sessions at the day-long event and regular conference proceedings. Surveys administered during the conference will be used to assess attendees' experiences and improve the second iteration of TLC at APSA in 2019. The program committee for next year's TLC at APSA is building on the momentum provided by the inaugural conference, and they plan to provide innovative venues for introducing quality scholarship on teaching and learning in the discipline. 